Review Article: Cooperation ${ }^{\mathrm{N}} \ldots \ldots \ldots \ldots \ldots \ldots \ldots \ldots \ldots \ldots \ldots \ldots \ldots \ldots \ldots \ldots$

J. Periam Danton

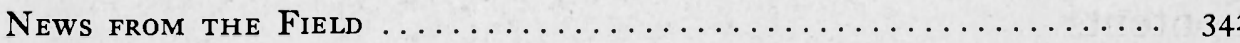

\title{
Change of Policy in the Distribution of Printed Cards by the Library of Congress to Depository Libraries
}

$I^{N}$ $\mathrm{N}$ VIEW of the projected publication of the Library of Congress printed cards in book form, the library issues this statement to define changes in requirements to be made of libraries receiving its printed cards on deposit.

The Library of Congress will continue to distribute new cards to regular depository libraries whether or not they subscribe to the set in book form.

A depository library which subscribes to the catalog of printed cards to be published under the auspices of the Association of Research Libraries may choose one of the following courses of action as regards depository cards distributed August I, I942, or later:

(I) It may file the new cards as a separate catalog.

(2) It may continue to interfile the new cards with the present depository set.

The Library of Congress will require the regular depository library which subscribes to the set in book form to inform the library as to which of the above methods will be followed.
In the event that the depository library chooses the first of these alternatives, the Library of Congress will entertain a proposal for the use of the present depository cards in the development of a local or regional union catalog, or other suitable bibliographical project. Failing a suitable proposal for local use of the depository set, it should be returned to the Library of Congress, after due notice.

Subscribers to the catalog in book form can establish a working supplement to it by purchasing for $\$ 42$ per year the proof sheets of the printed cards cut to card size and punched. The proof slips may be discarded when the supplementary volumes covering them are issued. If printed cards are desired instead of the proof sheets, these can be supplied by the Card Division of the Library of Congress at prices listed in the Handbook of Card Distribution.

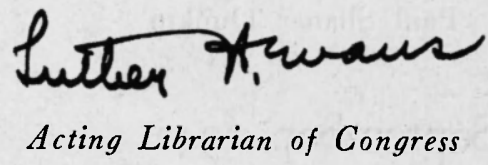

June 30 , 1942 